Article

\title{
Green Polyurethanes from Renewable Isocyanates and Biobased White Dextrins
}

\author{
Jakob Konieczny ${ }^{1,2}$ and Katja Loos $1,2, * \mathbb{D}$ \\ 1 Macromolecular Chemistry and New Polymeric Materials, Zernike Institute for Advanced Materials, \\ University of Groningen, Nijenborgh 4, 9747 AG Groningen, The Netherlands; jkonieczny845@gmail.com \\ 2 Dutch Polymer Institute (DPI), P.O. Box 902, 5600 AX Eindhoven, The Netherlands \\ * Correspondence: k.u.loos@rug.nl; Tel.: +31-50-3636867
}

Received: 11 September 2018; Accepted: 31 January 2019; Published: 3 February 2019

\begin{abstract}
Polyurethanes (PUs) are an important class of polymers due to their low density and thermal conductivity combined with their interesting mechanical properties-they are extensively used as thermal and sound insulators, as well as structural and comfort materials. Despite the broad range of applications, the production of PUs is still highly petroleum-dependent. The use of carbohydrates in PU synthesis has not yet been studied extensively, even though, as multihydroxyl compounds, they can easily serve as crosslinkers in PU synthesis. Partially or potentially biobased di-, tri- or poly-isocyanates can further be used to increase the renewable content of PUs. In our research, PU films could be easily produced using two bio-based isocyanates-ethyl ester L-lysine diisocyanate (LLDI] and ethyl ester L-lysine triisocyanate (LLTI)—, one commercial isocyanate-isophorone diisocyanate (IPDI), and a bio-based white dextrin (AVEDEX W80) as a crosslinker. The thermal and mechanical properties are evaluated and compared as well as the stability against solvents.
\end{abstract}

Keywords: starch; carbohydrates; polyurethanes; film formation; renewable resources

\section{Introduction}

Polyurethanes (PUs) are versatile polymers, created from the reaction between a polyol and a polyisocyanate, that are used in a large range of applications, such as automotive, furniture, construction, footwear, etc. The PU industry is strongly dependent on fossil-based polyols and polyisocyanates. Developing novel sustainable polyols from valuable biobased building blocks is a first step toward strong and durable development [1-3].

In recent years, the preparation of PUs from renewable sources such as vegetable oil-based materials [4], lignin [5], limonene [6], and even coffee grounds [7] has been receiving increasing attention because of economic and environmental concerns [8-13]. The use of carbohydrates in PU synthesis has not yet been studied extensively, even though, as multihydroxyl compounds [14-19], they can easily serve as crosslinkers in PU synthesis. Furthermore, they can impart mechanical strength, biodegradability, and biocompatibility to the produced PUs. Carbohydrates are reported to be embedded in PU networks by using them as composites/fillers and by covalent linkage with isocyanate to form crosslinked networks [20]. Solanki et al., for instance, synthesized castor oil-based PUs crosslinked with starch and reported excellent mechanical properties of the produced materials [21]. Carbohydrates, such as cellulose [22-26] or starch [27] nanocrystals, have been used as useful fillers in PUs. We have recently reported PU synthesis and film formation capacity using an asymmetric cyclic aliphatic diisocyanate and acetylated and pristine partially hydrolyzed amylopectin/white dextrin (AVEDEX W80) as a crosslinker [28,29].

The next logical step towards a greener PU formulation is then, of course, the use of partially or potentially biobased di-, tri- or poly-isocyanates. While synthetic pathways to biobased isocyanates still 
require phosgene as a petroleum-based reagent, several commercial isocyanates with high renewable content exist, such as isocyanates based on fatty acids or amino acids.

L-lysine-based diisocyanates have frequently been used for biomedical PUs in the last several years as drug delivery systems, hydrogels, implant materials, etc. [30-36]. In some very inspiring recent research, the L-lysine based ethyl ester L-lysine diisocyanate was compared to petrol-based hexamethylene diisocyanate, and isophorone diisocyanate in terms of reactivity and final properties of the PU [37-41] and even fully renewable thermoplastic poly(ester urethane urea)s were produced [42]. More studies on enzymatic breakdown/biodegradability of (biobased) PUs are conducted in recent years proving the importance of environmentally friendly PU applications [9,43-47].

In our previous work, we found that pristine AVEDEX W80 resulted in the best PU films $[29,48]$ (i.e., with no cracks, inhomogeneity, or swelling) and we, therefore, continue with this system and two bio-based isocyanates-ethyl ester L-lysine diisocyanate (LLDI) and ethyl ester L-lysine triisocyanate (LLTI)—and one commercial isocyanate-isophorone diisocyanate (IPDI). The optimal reaction conditions in terms of casting time and temperature, isocyanate used, amount of solvent, and excess of isocyanate were also determined.

\section{Materials and Methods}

Already degraded amylopectin-white dextrin (AVEDEX W80) was obtained from AVEBE (Veendam, The Netherlands) and used without further purification. Iodine was provided by Boom and purified by sublimation twice. Isophorone diisocyanate (IPDI) was provided by Merck (Darmstadt, Germany) and ethyl ester L-lysine diisocyanate (LLDI) and ethyl ester L-lysine triisocyanate (LLTI) were provided by Shanghai Infine Chemicals Co. Ltd. (Shanghai, China). Acetic anhydride $\left(\left(\mathrm{CH}_{3} \mathrm{CO}\right)_{2} \mathrm{O}\right)$ $(\geq 99.0 \%)$ and propionic anhydride $\left(\left(\mathrm{CH}_{3} \mathrm{CH}_{2} \mathrm{CO}\right)_{2} \mathrm{O}\right)(\geq 96.0 \%)$ were provided by Fluka (Bucharest, Romania), sodium thiosulfate $\left(\mathrm{NaS}_{2} \mathrm{O}_{3}\right)(\geq 98.0 \%)$ and DMSO $(99 \%)$ were provided by Sigma-Aldrich (St. Louis, MO, USA) and ethanol ( $\geq 99 \%$ ) was purchased from Merck (Darmstadt, Germany) and used without further purification.

Attenuated total reflection-Fourier transform infrared (ATR-FTIR) measurements were characterized by a Bruker IFS88 FT-IR spectrometer (Leiderdorp, The Netherlands). For each sample, 128 scans were performed.

Thermal transitions were measured by differential scanning calorimetry (DSC) on a TA-Instruments Q1000 (Hertfordshire, UK). The heating and cooling rates were $10^{\circ} \mathrm{C} / \mathrm{min}$. To remove the remaining water and solvents in the polymer, the tested sample was first heated to $100{ }^{\circ} \mathrm{C}$ at $10{ }^{\circ} \mathrm{C} / \mathrm{min}$, maintained at this temperature for $5 \mathrm{~min}$, and then cooled to room temperature before the standard DSC measurement. Each sample was run for 4 cycles, and the $\mathrm{T}_{\mathrm{g}}$ was calculated from the second.

Specimens were made from PU samples and were tested on a tensile tester to study their mechanical properties, such as stress-strain behavior and Young's modulus. The samples were kept between two Teflon plates to ensure a smooth and straight sample form, especially samples that had the tendency to break easily. Mechanical properties were tested on an Instron Tensile Tester (Boechout, Belgium) with a pulling speed of $10 \mathrm{~mm} / \mathrm{min}$. The distance between the clamps was $25 \mathrm{~mm}$ with a pressure of 7 bar.

\subsection{Crosslinking of Acylated Polyols with Di- and Tri-Iisocyanates}

Point two gram polyol AVEDEX W80 was dissolved in $7.5 \mathrm{~mL}$ of solvent (DMSO). A 1.05-fold excess of a di- and/or tri-isocyanate (i.e., a 1.05-fold excess of -NCO groups to -OH groups) was added, the mixture was stirred for 1 to $2 \mathrm{~min}$, and the resulting homogenous mixture was poured onto a petri dish. The petri dish was placed on a heating block at a defined temperature $\left(120^{\circ} \mathrm{C}\right)$, covered with filter paper and the heating block was sealed to provide a solvent atmosphere. After a defined period of time, the petri dish was removed from the heating block. 


\subsection{Resistance against Organic Solvents}

To investigate the resistance of the obtained polyurethane films against organic solvents, samples were weighed, after drying to constant weight, before and after immersing them in an organic solvent.

\section{Results}

The synthesis of polyurethane films by the crosslinking of carbohydrates as polyol components with isocyanates - see Scheme 1-was successfully conducted. The selection of isocyanates available for PU synthesis with polysaccharide polyols is almost unrestricted. As aromatic isocyanates might introduce a color into the final material, we did not consider them here. Two bio-based isocyanates—ethyl ester L-lysine diisocyanate (LLDI) and ethyl ester L-lysine triisocyanate (LLTI)—and one commercial isocyanate-isophorone diisocyanate (IPDI)—were used.

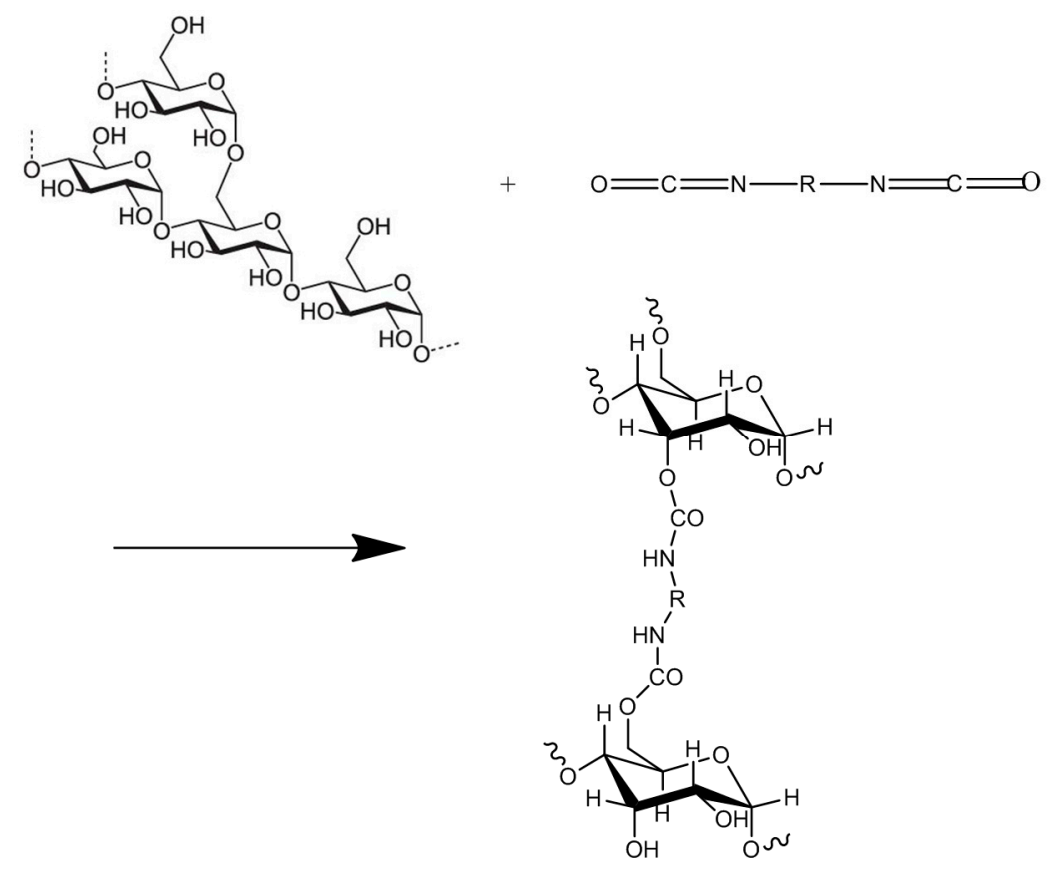

Scheme 1. Reaction scheme of the crosslinking of carbohydrates as polyol components with isocyanates.

PUs derived from the diisocyanates IPDI and LLDI were too hard and brittle to test after drying. LLTI-based PUs behaved more like a rubber than a plastic; after drying the material became hard, but it was still flexible. PUs from IPDI always resulted in a hard and brittle material (after drying), but they are the only ones that are transparent due to the yellow color of the biobased isocyanates. PUs from LLDI also became brittle after drying, but the material was soft and easy to scratch.

FT-IR spectra of all films show successful PU synthesis; Figure 1 shows the FT-IR spectrum of an IPDI-based PU. The peaks of the amide I and amide II bands from the newly formed polyurethane linkages are visible at $1550 \mathrm{~cm}^{-1}$ and $1650 \mathrm{~cm}^{-1}$ respectively. All materials are not fully reacted, i.e., not all of the $\mathrm{OH}$-functions of the polyol formed urethane linkages with the di- and tri-isocyanates, not even while using a $50 \%$ excess of isocyanate. It seems to be impossible to convert all free $\mathrm{OH}$ groups in pristine AVEDEX W80 as crosslinking becomes too high. In our previous work, we also observed that PU films with an excessively high crosslinking become brittle so that a full conversion is not desirable from the start. 


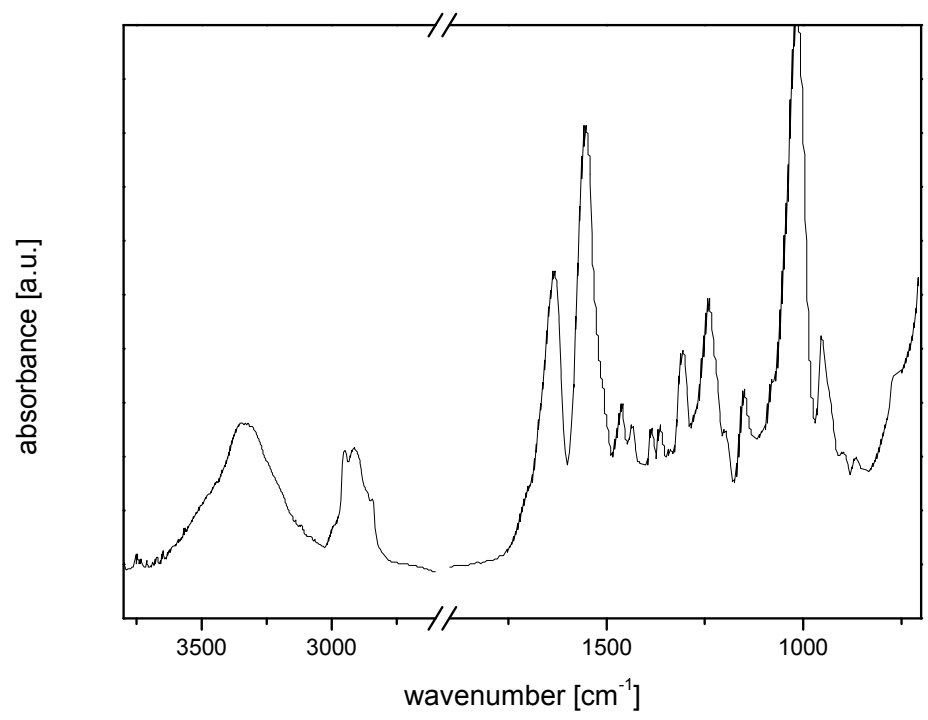

Figure 1. Fourier transform infrared (FT-IR) spectrum of isophorone diisocyanate (IPDI) based polyurethanes (PU) (75\% IPDI/25\% ethyl ester L-lysine triisocyanate (LLTI)).

To improve the properties of synthesized PUs, we decided to perform experiments with mixtures of isocyanates from this series. Two series of experiments with different ratios of two isocyanates were carried out, with the diisocyanate always the main component of the isocyanate and up to $50 \%$ (by volume) LLTI as a "co"-isocyanate. Combinations of the two diisocyanates were also prepared, with different ratios of these two isocyanates.

Mechanical properties of the produced films were tested on an Instron Tensile Tester with a pulling speed of $10 \mathrm{~mm} / \mathrm{min}$ and are summarized in Table 1 -the stress-strain curves are shown in Figures $2-4$.

Table 1. Average Young's modulus, maximum stress and maximum strain of PUs with different isocyanate ratios.

\begin{tabular}{ccccc}
\hline \% LLTI & \% IPDI & Young's Modulus (MPa) & Stress at Max Load (MPa) & \% Strain at Max Load \\
\hline 8 & 92 & 1126 & 9 & 2 \\
12 & 88 & 1536 & 33 & 2 \\
25 & 75 & 1554 & 44 & 3 \\
29 & 71 & 1427 & 46 & 5 \\
\hline \% LLDI & \% IPDI & & & 2 \\
\hline 42 & 58 & 1600 & 22 & 3 \\
50 & 50 & 1501 & 41 & \\
58 & 42 & 1585 & & 60 \\
\hline \% LLDI & \% LLTI & & 2 & 92 \\
\hline 34 & 66 & 22 & 6 & 123 \\
\hline 50 & 50 & 195 & 2 & 2 \\
\hline
\end{tabular}



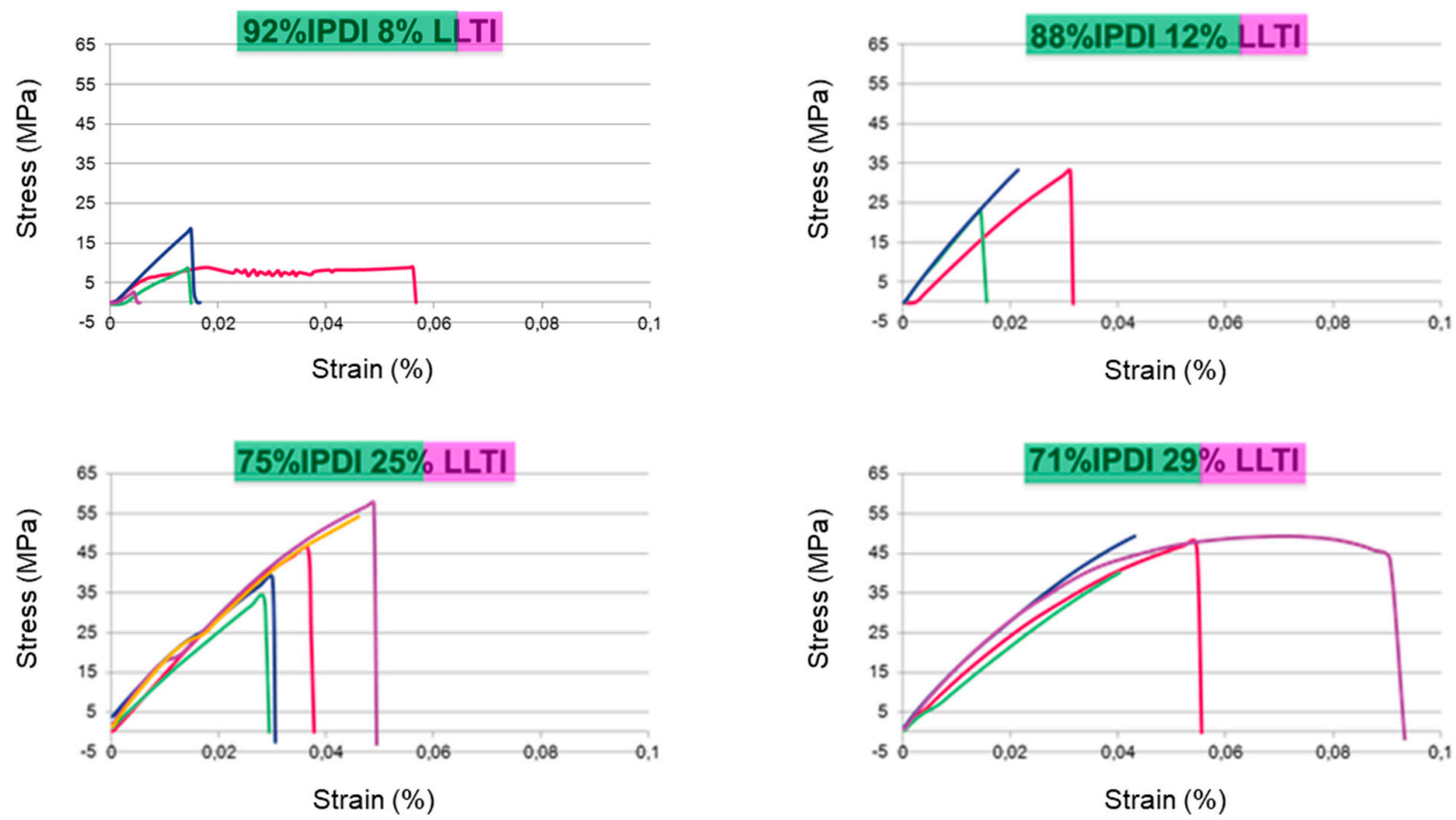

Figure 2. Stress-strain behavior of PUs with different IPDI/LLTI ratios.
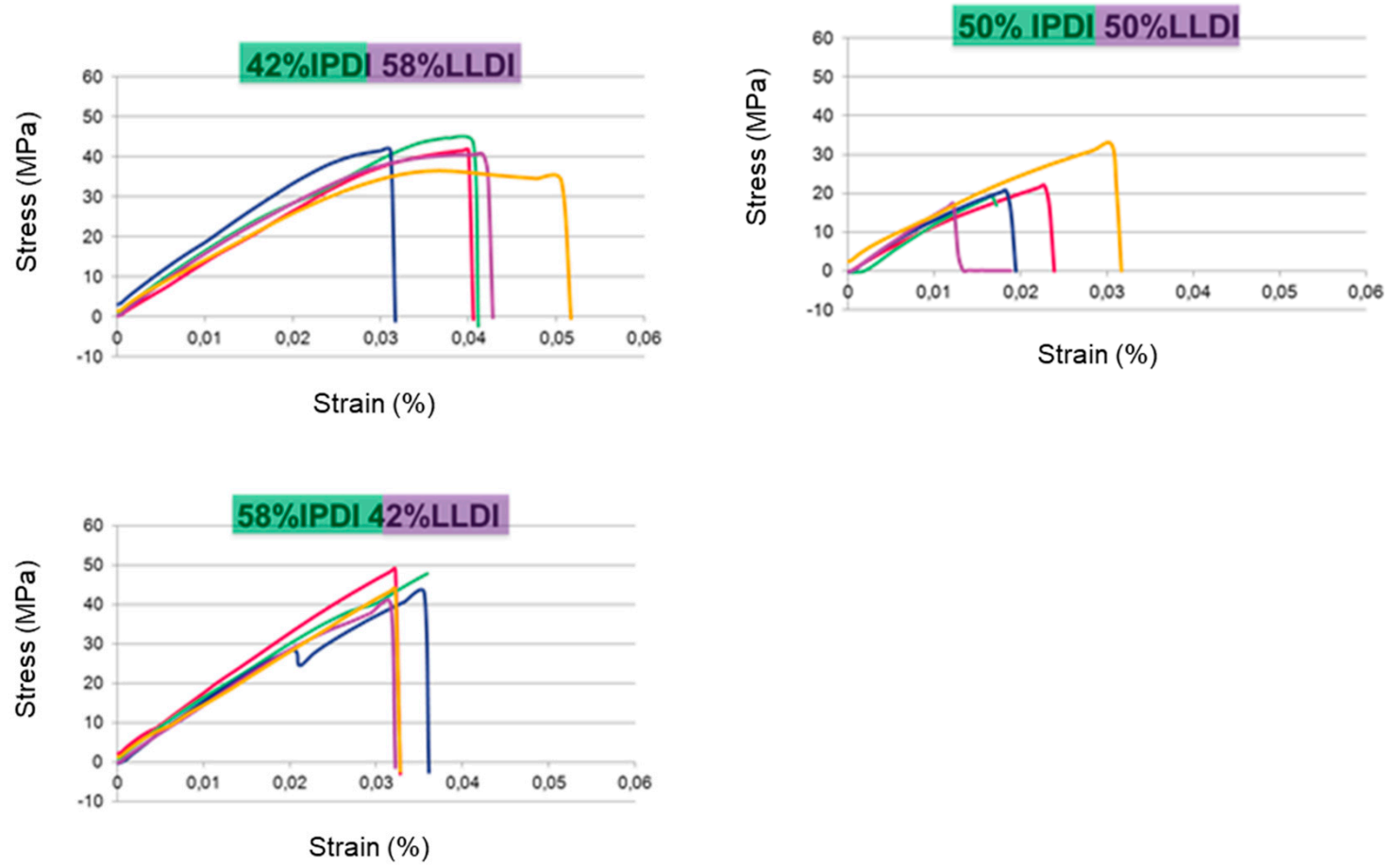

Figure 3. Stress-strain behavior of PUs with different IPDI/ ethyl ester L-lysine diisocyanate (LLDI) ratios. 

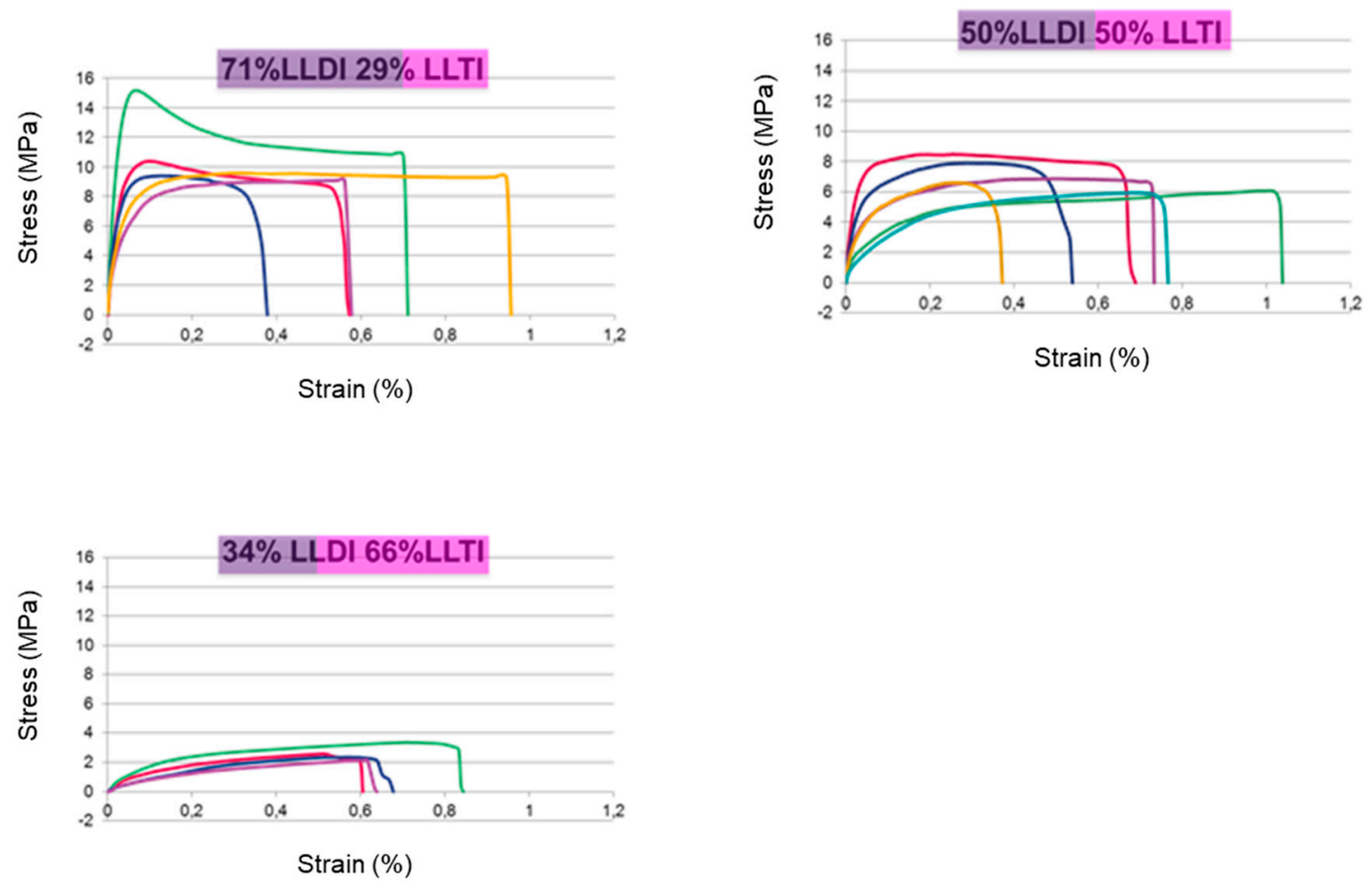

Figure 4. Stress-strain behavior of PUs with different LLDI/LLTI ratios.

Gradual replacement of the hard diisocyanate with the soft triisocyanate resulted in a softer, less rigid and breakable material. At 29\% LLTI, the strain at maximum load was twice as large as at $12 \%$ LLTI and samples were much more flexible. The curve progression was straight at $8 \%$ LLTI, but at $29 \%$ LLTI the curve already looked much more like a stress-strain curve from a rubber, with a plateau at its maximum and much higher strain than at 8\% LLTI (see Figure 2).

Shifting the ratio of two diisocyanates slightly from a 1:1 ratio toward either side did not change the mechanical properties of the material. As seen in Table 1, neither the average modulus, nor the stress or the strain at max load change significantly. Only the curve progression becomes more rubbery, like in the sample with 58\% LLDI.

Gradually replacing LLDI with LLTI during solvent casting resulted in a much harder material compared to PUs consisting only of LLDI. At approximately 30\% LLTI, the material has the most desirable properties, as the surface is hard, but the whole sample is still flexible enough to bend, and the strain before breaking is over $100 \%$. The LLDI/LLTI PU is by far the one with the greatest strain at maximum load (Table 1).

Increasing the percentage of LLTI changes the PU properties even further, with the flexibility almost lost and the stress the sample can withstand before breaking very low compared with the other combinations of isocyanates. The maximum strain is also greatly reduced with an increase of LLTI above $30 \%$.

The thermal properties of the produced PUs were assessed by differential scanning calorimetry. The highest $T_{g}$ was observed for the IPDI-based PU $\left(T_{g}=157^{\circ} \mathrm{C}\right)$. To investigate the dependence of $T_{g}$ on the ratio of isocyanates, samples with different ratios were tested; this data is presented in Figure 5. In the case of the IPDI-based PUs. the effect is clearly visible; lowering the IPDI ratio lowers the $T_{g}$. In the case of the LLDI/LLTI-based PUs, change of the LLDI/LLTI ratio does not result in significant change in $\mathrm{T}_{\mathrm{g}}$; increasing the percentage of LLDI results in $\mathrm{T}_{\mathrm{g}}$ being slightly shifted towards lower temperatures. At this point, we cannot explain the one outlier at around $80 \%$ LLDI content. 

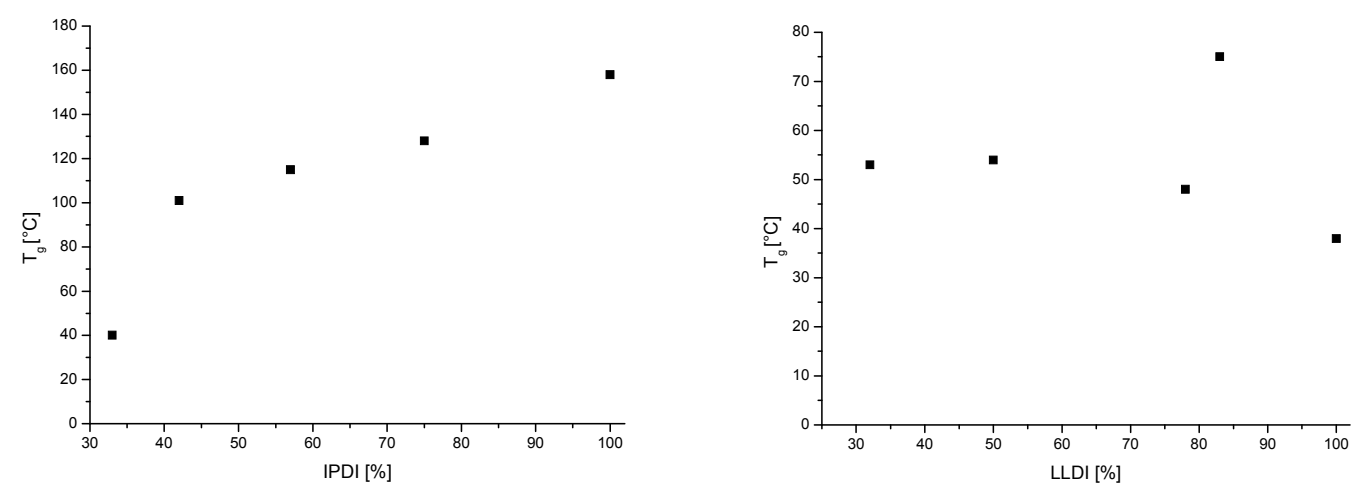

Figure 5. Relationship between $\mathrm{T}_{\mathrm{g}}$ and isocyanate ratio of IPDI-based (left) and LLDI-based (right) PU films.

To test the resistance of the PU films against organic solvents, different samples were chosen and immersed in DMSO for $24 \mathrm{~h}$. DMSO was chosen because it showed the most aggressive behavior toward the films. The difference in weight before and after immersion after drying until constant weight was calculated; this data is presented in Table 2. As observed by FT-IR measurements, the samples are not changed chemically during the solvent resistance test, indicating that the weight loss mainly results from washing away of unreacted polyol from the PU sample (as indicated by the lower OH-peak and higher amide I and II peaks). Samples made with IPDI seem to be more resistant against attacks from DMSO. The maximum weight loss in samples with IPDI is $7 \%$, as compared to $12.5 \%$ for LLTI and almost $30 \%$ for LLDI.

Table 2. Weight loss of different ethyl ester polyurethanes (PU) samples after immersion in DMSO for $1 d$.

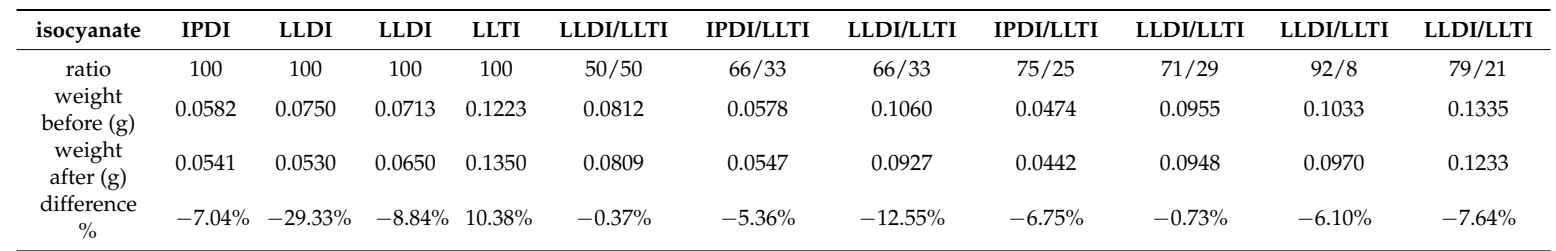

\section{Conclusions}

Unmodified AVEDEX W80 was able to form homogenous films with the tested di- and tri-isocyanates, after optimization of several reaction conditions. With commercially used IPDI, the resulting material is transparent, rigid, and tends to break quite easily, especially after drying in the vacuum oven.

PUs derived from LLDI are flexible, but rather milky than transparent and they experience a coarse surface. They are more flexible than the IPDI based PUs but also tend to crack when fully dry as proven by tensile tests. As the biobased LLDI and LLTI are colored, the resulting films have a slightly yellow color (more pronounced in the PU films of LLTI).

Addition of the trifunctional isocyanate LLTI to either IPDI- or LLDI-based formulations resulted in a dry material, which has a high scratch resistance but is still flexible without breaking. Ratios of the isocyanates play an important role in the final properties of the material.

In general, the IPDI-based PUs shows higher stability in DMSO than the biobased. Additionally, the biobased PUs tend to swell in organic solvents, which is not the case for IPDI-based PUs. Besides differences in brittleness, differences in $\mathrm{T}_{\mathrm{g}}$ can be observed in all four PUs. Combining two of these isocyanates results in changes in $\mathrm{T}_{\mathrm{g}}$, especially while replacing IPDI with LLDI, resulting in a drop in $\mathrm{T}_{\mathrm{g}}$. Gradually replacing LLDI with LLTI does not result in significant $\mathrm{T}_{\mathrm{g}}$ changes in the material. 
The mechanical properties of these materials depend on the isocyanate used for the PU formulation. If IPDI is the major component in the isocyanate mixture, the mechanical behavior is that of a hard and brittle material. Addition of the trifunctional isocyanate results in a much more rubbery material, visible in the stress-strain diagram. The slope of the curve starts to decrease at some point, reaching a plateau, which then leads to "necking" in the tensile tests.

Author Contributions: J.K. designed and performed the experiments reported in this publication and wrote parts of the paper. K.L. provided guidance, idea and suggestion to the research, helped in analyzing some data, revising and writing this paper.

Funding: This research forms part of the research programme of the Dutch Polymer Institute (DPI), project \#673.

Acknowledgments: This research forms part of the research programme of the Dutch Polymer Institute (DPI), project \#673.

Conflicts of Interest: The authors declare no conflict of interest.

\section{Abbreviations}

PU

AVEDEX W80 amylopectin/white dextrin

LLDI ethyl ester L-lysine diisocyanate

LLTI ethyl ester L-lysine triisocyanate

IDPI isophorone diisocyanate

\section{References}

1. Dworakowska, S.; Bogdal, D.; Zaccheria, F.; Ravasio, N. The role of catalysis in the synthesis of polyurethane foams based on renewable raw materials. Catal. Today 2014, 223, 148-156. [CrossRef]

2. Kaiser, T.; Rathgeb, A.; Gertig, C.; Bardow, A.; Leonhard, K.; Jupke, A. Carbon2polymer-conceptual design of a co2-based process for the production of isocyanates. Chemie Ingenieur Technik 2018, 90, 1497-1503. [CrossRef]

3. Wegener, G.; Brandt, M.; Duda, L.; Hofmann, J.; Klesczewski, B.; Koch, D.; Kumpf, R.J; Orzesek, H.; Pirkl, H.G.; Six, C.; et al. Trends in industrial catalysis in the polyurethane industry. Appl. Catal. A Gen. 2001, 221, 303-335. [CrossRef]

4. Chuayjuljit, S.; Maungchareon, A.; Saravari, O. Preparation and properties of palm oil-based rigid polyurethane nanocomposite foams. J. Reinf. Plast. Compos. 2010, 29, 218-225. [CrossRef]

5. Bernardini, J.; Cinelli, P.; Anguillesi, I.; Coltelli, M.B.; Lazzeri, A. Flexible polyurethane foams green production employing lignin or oxypropylated lignin. Eur. Polym. J. 2015, 64, 147-156. [CrossRef]

6. Gupta, R.K.; Ionescu, M.; Radojcic, D.; Wan, X.; Petrovic, Z.S. Novel renewable polyols based on limonene for rigid polyurethane foams. J. Polym. Environ. 2014, 22, 304-309. [CrossRef]

7. Gama, N.V.; Soares, B.; Freire, C.S.R.; Silva, R.; Neto, C.P.; Barros-Timmons, A.; Ferreira, A. Bio-based polyurethane foams toward applications beyond thermal insulation. Mater. Des. 2015, 76, 77-85. [CrossRef]

8. Noreen, A.; Zia, K.M.; Zuber, M.; Tabasum, S.; Zahoor, A.F. Bio-based polyurethane: An efficient and environment friendly coating systems: A review. Prog. Org. Coat. 2016, 91, 25-32. [CrossRef]

9. Suthapakti, K.; Molloy, R.; Leejarkpai, T. Disintegration testing of biodegradable poly(l-lactide)/ thermoplastic polyurethane melt blended films. Chiang Mai J. Sci. 2018, 45, 2079-2091.

10. Uscategui, Y.L.; Diaz, L.E.; Valero, M.F. Biomedical applications of polyurethanes. Quimica Nova 2018, 41, 434-445. [CrossRef]

11. Das, S.; Pandey, P.; Mohanty, S.; Nayak, S.K. Evaluation of biodegradability of green polyurethane/nanosilica composite synthesized from transesterified castor oil and palm oil based isocyanate. Int. Biodeterior. Biodegrad. 2017, 117, 278-288. [CrossRef]

12. Nakhoda, H.M.; Dahman, Y. Mechanical properties and biodegradability of porous polyurethanes reinforced with green nanofibers for applications in tissue engineering. Polym. Bull. 2016, 73, 2039-2055. [CrossRef]

13. Duguay, D.G.; Labow, R.S.; Santerre, J.P.; McLean, D.D. Development of a mathematical-model describing the enzymatic degradation of biomedical polyurethanes. 1. Background, rationale and model formulation. Polym. Degrad. Stab. 1995, 47, 229-249. [CrossRef] 
14. van der Vlist, J.; Schonen, I.; Loos, K. Utilization of glycosyltransferases for the synthesis of a densely packed hyperbranched polysaccharide brush coating as artificial glycocalyx. Biomacromolecules 2011, 12, 3728-3732. [CrossRef] [PubMed]

15. Ciric, J.; Woortman, A.J.; Loos, K. Analysis of isoamylase debranched starches with size exclusion chromatography utilizing pfg columns. Carbohydr. Polym. 2014, 112, 458-461. [CrossRef] [PubMed]

16. Ciric, J.; Rolland-Sabate, A.; Guilois, S.; Loos, K. Characterization of enzymatically synthesized amylopectin analogs via asymmetrical flow field flow fractionation. Polymer 2014, 55, 6271-6277. [CrossRef]

17. Loos, K.; von Braunmuhl, V.; Stadler, R.; Landfester, K.; Spiess, H.W. Saccharide modified silica particles by enzymatic grafting. Macromol. Rapid Commun. 1997, 18, 927-938. [CrossRef]

18. van der Vlist, J.; Palomo Reixach, M.; van der Maarel, M.; Dijkhuizen, L.; Schouten, A.J.; Loos, K. Synthesis of branched polyglucans by the tandem action of potato phosphorylase and deinococcus geothermalis glycogen branching enzyme. Macromol. Rapid Commun. 2008, 29, 1293-1297. [CrossRef]

19. Mazzocchetti, L.; Tsoufis, T.; Rudolf, P.; Loos, K. Enzymatic synthesis of amylose brushes revisited: Details from x-ray photoelectron spectroscopy and spectroscopic ellipsometry. Macromol. Biosci. 2014, 14, 186-194. [CrossRef]

20. Solanki, A.; Das, M.; Thakore, S. A review on carbohydrate embedded polyurethanes: An emerging area in the scope of biomedical applications. Carbohydr. Polym. 2018, 181, 1003-1016. [CrossRef]

21. Solanki, A.; Mehta, J.; Thakore, S. Structure-property relationships and biocompatibility of carbohydrate crosslinked polyurethanes. Carbohydr. Polym. 2014, 110, 338-344. [CrossRef] [PubMed]

22. Septevani, A.A.; Evans, D.A.C.; Annamalai, P.K.; Martin, D.J. The use of cellulose nanocrystals to enhance the thermal insulation properties and sustainability of rigid polyurethane foam. Ind. Crop. Prod. 2017, 107, 114-121. [CrossRef]

23. Aranguren, M.I.; Marcovich, N.E.; Salgueiro, W.; Somoza, A. Effect of the nano-cellulose content on the properties of reinforced polyurethanes. A study using mechanical tests and positron anihilation spectroscopy. Polym. Test. 2013, 32, 115-122. [CrossRef]

24. Auad, M.L.; Contos, V.S.; Nutt, S.; Aranguren, M.I.; Marcovich, N.E. Characterization of nanocellulose-reinforced shape memory polyurethanes. Polym. Int. 2008, 57, 651-659. [CrossRef]

25. Wu, G.M.; Chen, J.; Huo, S.P.; Liu, G.F.; Kong, Z.W. Thermoset nanocomposites from two-component waterborne polyurethanes and cellulose whiskers. Carbohydr. Polym. 2014, 105, 207-213. [CrossRef] [PubMed]

26. Wu, Q.J.; Henriksson, M.; Liu, X.; Berglund, L.A. A high strength nanocomposite based on microcrystalline cellulose and polyurethane. Biomacromolecules 2007, 8, 3687-3692. [CrossRef] [PubMed]

27. Zou, J.W.; Zhang, F.; Huang, J.; Chang, P.R.; Su, Z.M.; Yu, J.H. Effects of starch nanocrystals on structure and properties of waterborne polyurethane-based composites. Carbohydr. Polym. 2011, 85, 824-831. [CrossRef]

28. Konieczny, J.; Loos, K. Facile esterification of degraded and non-degraded starch. Macromol. Chem. Phys. 2018. [CrossRef]

29. Konieczny, J.; Loos, K. Bio-based polyurethane films using white dextrins. J. Appl. Polym. Sci. 2018. [CrossRef]

30. Fu, H.G.; Gao, H.; Wu, G.L.; Wang, Y.O.; Fan, Y.G.; Ma, J.B. Preparation and tunable temperature sensitivity of biodegradable polyurethane nanoassemblies from diisocyanate and poly(ethylene glycol). Soft Matter 2011, 7, 3546-3552. [CrossRef]

31. Han, J.A.; Cao, R.W.; Chen, B.; Ye, L.; Zhang, A.Y.; Zhang, J.A.; Feng, Z.G. Electrospinning and biocompatibility evaluation of biodegradable polyurethanes based on l-lysine diisocyanate and l-lysine chain extender. J. Biomed. Mater. Res. Part A 2011, 96A, 705-714. [CrossRef] [PubMed]

32. Marcos-Fernandez, A.; Abraham, G.A.; Valentin, J.L.; San Roman, J. Synthesis and characterization of biodegradable non-toxic poly(ester-urethane-urea)s based on poly(epsilon-caprolactone) and amino acid derivatives. Polymer 2006, 47, 785-798. [CrossRef]

33. Mathew, S.; Baudis, S.; Neffe, A.T.; Behl, M.; Wischke, C.; Lendlein, A. Effect of diisocyanate linkers on the degradation characteristics of copolyester urethanes as potential drug carrier matrices. European Journal of Pharm. Biopharm. 2015, 95, 18-26. [CrossRef] [PubMed]

34. Storey, R.F.; Wiggins, J.S.; Puckett, A.D. Hydrolyzable poly(ester-urethane) networks from l-lysine diisocyanate and d,l-lactide epsilon-caprolactone homopolyester and copolyester triols. J. Polym. Sci. Part A Polym. Chem. 1994, 32, 2345-2363. [CrossRef] 
35. Wang, Z.G.; Yu, L.Q.; Ding, M.M.; Tan, H.; Li, J.H.; Fu, Q.A. Preparation and rapid degradation of nontoxic biodegradable polyurethanes based on poly(lactic acid)-poly(ethylene glycol)-poly(lactic acid) and l-lysine diisocyanate. Polym. Chem. 2011, 2, 601-607. [CrossRef]

36. Whang, C.H.; Lee, H.K.; Kundu, S.; Murthy, S.N.; Jo, S. Pluronic-based dual-stimuli sensitive polymers capable of thermal gelation and ph-dependent degradation for in situ biomedical application. J. Appl. Polym. Sci. 2018, 135. [CrossRef] [PubMed]

37. Gustini, L.; Lavilla, C.; Finzel, L.; Noordover, B.A.J.; Hendrix, M.; Koning, C.E. Sustainable coatings from bio-based, enzymatically synthesized polyesters with enhanced functionalities. Polym. Chem. 2016, 7,6586-6597. [CrossRef]

38. Gustini, L.; Noordover, B.A.J.; Gehrels, C.; Dietz, C.; Koning, C.E. Enzymatic synthesis and preliminary evaluation as coating of sorbitol-based, hydroxy-functional polyesters with controlled molecular weights. Eur. Polym. J. 2015, 67, 459-475. [CrossRef]

39. Li, Y.Y.; Noordover, B.A.J.; van Benthem, R.; Koning, C.E. Property profile of poly(urethane urea) dispersions containing dimer fatty acid-, sugar- and amine acid-based building blocks. Eur. Polym. J. 2014, 59, 8-18. [CrossRef]

40. Li, Y.Y.; Noordover, B.A.J.; van Benthem, R.; Koning, C.E. Reactivity and regio-selectivity of renewable building blocks for the synthesis of water-dispersible polyurethane prepolymers. ACS Sustain. Chem. Eng. 2014, 2, 788-797. [CrossRef]

41. Li, Y.Y.; Noordover, B.A.J.; van Benthem, R.; Koning, C.E. Bio-based poly(urethane urea) dispersions with low internal stabilizing agent contents and tunable thermal properties. Prog. Org. Coat. 2015, 86, 134-142. [CrossRef]

42. Tang, D.L.; Thiyagarajan, S.; Noordover, B.A.J.; Koning, C.E.; van Es, D.S.; van Haveren, J. Fully renewable thermoplastic poly(ester urethane urea)s from bio-based diisocyanates. J. Renew. Mater. 2013, 1, 222-229. [CrossRef]

43. Acik, G.; Kamaci, M.; Altinkok, C.; Karabulut, H.R.F.; Tasdelen, M.A. Synthesis and properties of soybean oil-based biodegradable polyurethane films. Prog. Org. Coat. 2018, 123, 261-266. [CrossRef]

44. Joo, Y.S.; Cha, J.R.; Gong, M.S. Biodegradable shape-memory polymers using polycaprolactone and isosorbide based polyurethane blends. Mater. Sci. Eng. C Mater. Biol. Appl. 2018, 91, 426-435. [CrossRef] [PubMed]

45. Loredo, A.; Arguello, A.; Rodriguez-Herrera, R.; Gutierrez-Sanchez, G.; Escamilla, A.; Aguilar, C. Fungal biodegradation of rigid polyurethane. Quimica Nova 2017, 40, 885-889.

46. Suthapakti, K.; Molloy, R.; Punyodom, W.; Nalampang, K.; Leejarkpai, T.; Topham, P.D.; Tighe, B.J. Biodegradable compatibilized poly(l-lactide)/thermoplastic polyurethane blends: Design, preparation and property testing. J. Polym. Environ. 2018, 26, 1818-1830. [CrossRef]

47. Zheng, L.C.; Li, C.C.; Xiao, Y.N.; Zhang, B.; Wang, Z.D. Biodegradable anti-fouling materials. Prog. Chem. 2017, 29, 824-832.

48. Konieczny, J.; Loos, K. Polyurethane coatings based on renewable white dextrins and isocyanate trimers. Macromol. Rapid Commun. 2019. [CrossRef]

(C) 2019 by the authors. Licensee MDPI, Basel, Switzerland. This article is an open access article distributed under the terms and conditions of the Creative Commons Attribution (CC BY) license (http:/ / creativecommons.org/licenses/by/4.0/). 